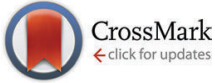

Cite this: New J. Chem., 2016, 40, 7958

Received (in Nottingham, UK)

3rd May 2016,

Accepted 19th July 2016

DOI: 10.1039/c6nj01399f

www.rsc.org/njc

\section{Selective glucose conversion to 5-hydroxymethylfurfural (5-HMF) instead of levulinic acid with MIL-101Cr MOF-derivatives $\uparrow$}

\author{
Annika Herbst and Christoph Janiak*
}

The catalytic conversion of glucose to 5-hydroxymethylfurfural (5-HMF) is highly desirable, but the 5 -HMF yield obtained using heterogeneous catalysts is still low compared to homogeneous catalysts, and the mechanism is not elucidated completely. In addition, the isolation and purification of 5-HMF still present a challenge as degradation reactions take place and side products form. The formation of 5-HMF from glucose has been reported using several solid acid catalysts; still metal-organic framework (MOF) catalysts could, so far, catalyze the cascade reaction of glucose to 5-HMF only in low yields of less than $16 \%$. Glucose conversion using MOFs is little investigated and here sulfonated MIL-101Cr $\left(\mathrm{MIL}-\mathrm{SO}_{3} \mathrm{H}\right)$ was found to achieve $29 \%$ conversion of glucose to $5-\mathrm{HMF}$ after $24 \mathrm{~h}$ in a THF : $\mathrm{H}_{2} \mathrm{O}(\mathrm{v}: \mathrm{v} 39: 1)$ mixture. The conversion of maltose resulted in 50\% 5-HMF yield (saccharide solutions were 5 wt \%). When the reaction was carried out in pure THF using MIL catalysts no product was formed, revealing the indispensability of water for the glucose-to-5-HMF conversion. Importantly, MIL-SO $3 \mathrm{H}$ preferentially leads to 5-HMF over levulinic acid (molar ratio 1:0.3), while the catalysts Amberlyst-15 and sulfuric acid form mostly levulinic acid in 5-HMF to levulinic acids ratios of $1: 3$ and $1: 10$, respectively. At the same time, MIL- $\mathrm{NO}_{2}$ is the most selective, yielding only 5-HMF and showing no formation of levulinic acid. Using $5-\mathrm{HMF}$ as a substrate did not result in any conversion to levulinic acid in the presence of $\mathrm{MIL}-\mathrm{SO}_{3} \mathrm{H}$, thereby ruling out the catalytic formation of levulinic acid from 5-HMF. Catalyst recycle experiments showed that $\mathrm{MIL}-\mathrm{SO}_{3} \mathrm{H}$ stays porous and crystalline, but becomes deactivated through fouling by humin formation. With the use of ethanol as an alternative reaction medium, the formation of insoluble humins could be prevented, but the yield of 5-HMF and 5-ethyl-HMF decreased.

\section{Introduction}

Biomass is highly attractive as a source for valuable chemicals and fuels, to save fossil fuels and reduce $\mathrm{CO}_{2}$ emissions therefrom. ${ }^{1,2}$ In particular, "waste” biomass from by-product streams (e.g. in agro industry, food sector, paper manufacturing and recycling) is investigated as feedstock for platform chemicals, e.g., 5-hydroxymethylfurfural (5-HMF) (Fig. 1), which can replace the petro-based chemicals and create new valuable products. ${ }^{3}$ Biomass of plants or algae consists mainly of lignocelluloses, which in turn contain cellulose, lignin and hemicelluloses. Cellulose represents the largest part with up to 50 weight $\%{ }^{4}$ Therefore the conversion of cellulose, respectively its glucose subunits, is of broad interest. The chemical conversion of glucose can proceed via acid-catalyzed

Institut für Anorganische Chemie und Strukturchemie, Heinrich-Heine Universität Düsseldorf, Universitätsstraße 1, D-40225 Düsseldorf, Germany.

E-mail:janiak@uni-duesseldorf.de

$\dagger$ Electronic supplementary information (ESI) available: Details of synthesis, methods, catalysis, NMR spectra, SEM images, powder X-ray diffractograms, $\mathrm{N}_{2}$ sorption isotherms, and potentiometric titrations. See DOI: 10.1039/c6nj01399f

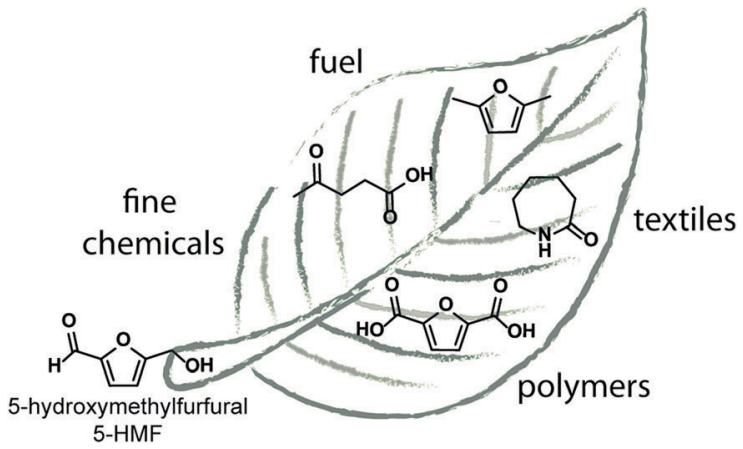

Fig. 1 5-HMF as precursor platform molecule for different products relevant to various industries.

dehydration, which presents challenging requirements to the catalyst, since a variety of products can be obtained (e.g. fructose, levoglucosan, other C5 or C6 monosaccharides, 5-HMF, furfural, lactic acid, levulinic acid and formic acid) (cf. Fig. 2). ${ }^{2}$ 


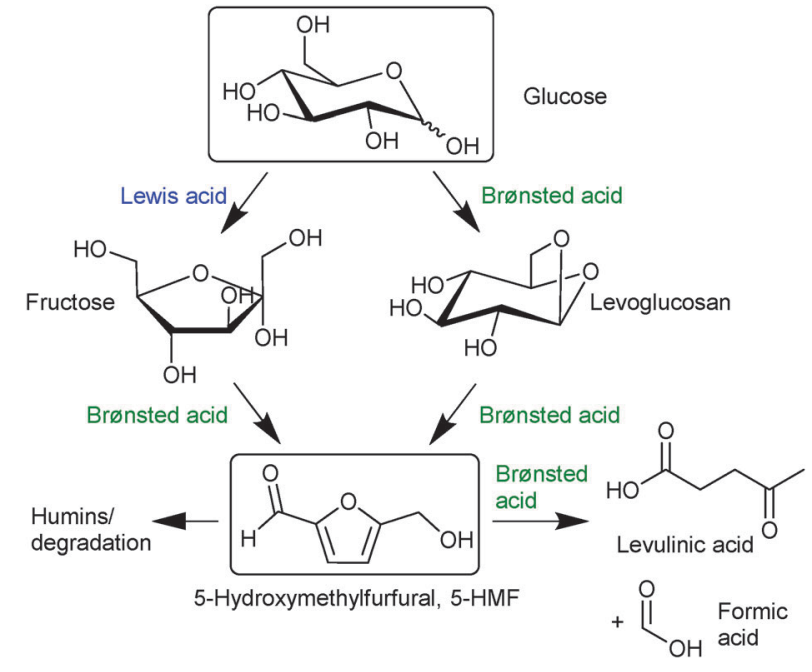

Fig. 2 Reaction scheme for 5 -HMF production from glucose. ${ }^{10}$

Among these glucose-dehydration products, 5-hydroxymethylfurfural (5-HMF) is of special interest because it can be converted to important polymer precursors such as 2,5-furan dicarboxylic acid (replacement of terephthalic acid), 1,6-hexanediol, caprolactam and 2,5-dimethylfuran, which is interesting as a fossil fuel alternative (Fig. 1). ${ }^{5}$ Consequently, enormous research interest arose with the aim of 5-HMF synthesis from glucose. During the last two years and also very recently, a number of excellent reviews have been published on this topic and provide a thorough overview. ${ }^{4,6}$

5 -HMF can be synthesized from glucose in aqueous media, DMSO, ionic liquids and in biphasic systems. Numerous catalysts have been tested which can be roughly classified into homogeneous Brønsted and Lewis acids $\left(\mathrm{H}_{2} \mathrm{SO}_{4}, \mathrm{CrCl}_{3}\right.$ or $\left.\mathrm{AlCl}_{3}\right)$ and solid acids (zeolites, resins and metal organic frameworks). A brief reaction sequence of the conversion of glucose to $\mathrm{HMF}$ is depicted in Fig. 2. Generally, 5-HMF is accessible via Lewisacidic isomerization of glucose to fructose and Brønsted acidic conversion to 5-HMF. ${ }^{7}$ Tessonnier et al. also investigated the selective isomerization to fructose via base catalysis, using amines, and found the same performance as the state-of-the-art Lewis acid catalysts with a yield of $32 \%$ and a selectivity of $63 \%$ for fructose after $20 \mathrm{~min}$ at $100{ }^{\circ} \mathrm{C} .{ }^{8,9}$ Huber et al. recently proposed a new mechanistic pathway for the formation of 5-HMF from cellulose and glucose which is based on acid catalysis through the intermediate levoglucosan instead of fructose (Fig. 2). ${ }^{10}$

Interestingly, the best 5 -HMF yield of $44 \%$ from cellulose was reported for a mixture of THF/water $40: 1$, using $\mathrm{H}_{2} \mathrm{SO}_{4}$ as the catalyst at $190{ }^{\circ} \mathrm{C}$. As postulated by Vlachos et al., the first step of glucose dehydration to levoglucosan in the Brønsted acidic mechanism is a protonation step (see the Mechanistic aspects section in the ESI $\dagger){ }^{11}$

Using separable and recyclable solid Brønsted acid instead of homogenous acid catalysts would lead to a further improvement in terms of green chemistry or green catalysis ${ }^{12}$ which requires the catalysts to be designed for easy separation from the reaction products and multi-time efficient reuse/ recycling. ${ }^{13-15}$
Metal-organic frameworks (MOFs), built from organic ligands (linkers) and metal nodes, are intensively investigated as heterogeneous catalysts. ${ }^{16,17}$ Usually, metal-organic frameworks are known for their Lewis acidity, which originates from open metal sites at the secondary building units (SBUs). ${ }^{18}$ Due to their porous structure, there are different possibilities to introduce Brønsted acid functionalities, discussed in a detailed review of Jiang and Yaghi. ${ }^{19}$ These include encapsulation of Brønsted acidic molecules in the cavity of MOFs, ligation of Brønsted acid groups to metal open sites or (post)synthetic functionalization of linkers with acidic moieties. There are examples for all three types of Brønsted acid functionalities in MOFs with subsequent catalysis. ${ }^{19}$ At present, there are only a handful of studies dealing with the conversion of biomass using MOFs. Li and Hensen et al. demonstrated the Brønsted acidic conversion of fructose and glucose to 5-HMF in DMSO by encapsulating phosphotungstic acid (PTA) in MIL-101Cr, albeit with a very low yield of $2 \%$ from glucose. ${ }^{20}$ Hatton reported a $\mathrm{MOF} /$ polymer composite material from MIL-101Cr and poly(N-bromomaleimide) which was able to convert fructose to $5-\mathrm{HMF}$ in $87 \%$ yield. ${ }^{21}$ A hybrid material containing PTA and ruthenium immobilized on MIL-100Cr was used for the conversion of cellulose and cellobiose into sorbitol. ${ }^{22}$ Matsuda and Kitagawa showed that linker functionalization in MIL-101Cr with $\mathrm{SO}_{3} \mathrm{H}$ enabled the hydrolysis of cellulose into monosaccharides in water. ${ }^{23}$ The same group studied the glucose to fructose isomerization ability of MIL$101 \mathrm{Cr}$ derivatives (with bdc- $\mathrm{NO}_{2},-\mathrm{NH}_{2},-\mathrm{SO}_{3} \mathrm{H}$; bdc = benzene1,4-dicarboxylate) in water. MIL-101Cr can have open metal sites that could act as catalysts for glucose to fructose isomerization. The highest activity was found for the $\mathrm{NO}_{2}$ - and the $\mathrm{SO}_{3} \mathrm{H}$-functionalized MIL-101Cr (18.4 and 21.6\% conversion to fructose, respectively, after $24 \mathrm{~h}, 100{ }^{\circ} \mathrm{C}, 0.2 \mathrm{~g}$ catalyst and $25 \mathrm{mg}$ glucose in $\left.2.0 \mathrm{~g} \mathrm{H}_{2} \mathrm{O}\right) .{ }^{24}$ Chen et al. investigated the activity of different $\mathrm{SO}_{3} \mathrm{H}$-functionalized MOFs (MIL-101Cr-SO ${ }_{3} \mathrm{H}$, UiO-66Zr-SO ${ }_{3} \mathrm{H}$ and MIL-53Al- $-\mathrm{SO}_{3} \mathrm{H}$ ) for the conversion of fructose into 5-HMF in DMSO with a maximum conversion of $90 \% .{ }^{25}$ To the best of our knowledge, until now no conversion of glucose to 5-HMF using MOF catalysts with yields higher than $16 \%$ has been reported. The glucose conversion of $16 \%$ was achieved using MIL-101Cr-PMAi-Br with a MIL-101Cr catalyst loading of $6 \mathrm{~mol} \%$ (or $21 \mathrm{wt} \%$ ) after $6 \mathrm{~h}$ in DMSO solvent, which made the product separation difficult $(\mathrm{PMAi}-\mathrm{Br}=$ $\operatorname{poly}(\mathrm{N}$-bromomaleimide-co-divinylbenzene $)) .{ }^{21}$

The isomerization of glucose to fructose can be carried out enzymatically but consumes over 10 million tons of glucose isomerase annually, representing the largest industrial use of immobilized enzymes. ${ }^{26}$ Glucose isomerase has a narrow operating window concerning $\mathrm{pH}$ and temperature. ${ }^{26}$ Therefore, it would be highly desirable to carry out a one-pot glucose-to-5HMF transformation without the need of a separate glucose-tofructose isomerization.

Recently, we showed that the catalyst activity of nitro-modified MIL-101Cr in benzaldehyde acetalization reaction originates from Brønsted acidity. ${ }^{27}$ It has been concluded that inside the pores of MIL-101Cr there exists high proton acidity through polarized chromium-coordinated water molecules (aqua ligands). It is a logical extension to investigate the activity of functionalized 
MIL-101Cr in the acid catalyzed glucose-to-5-HMF dehydration. We are aware of the better catalytic performance of other heterogeneous catalysts like sulfated $\mathrm{ZrO}_{2}$ or zeolite-beta, ${ }^{28}$ but our aim here is to investigate the potential of MOFs for this cascade reaction. Further, the chosen reaction media is THF/water in order to avoid high boiling solvents (DMSO) and to facilitate the separation of 5-HMF. MIL-101Cr and its derivatives are known for their high water stability and uptake. ${ }^{29,30}$ MIL-101 is also often used as a catalyst support, e.g., for metal ${ }^{31}$ or metal oxide nanoparticles. ${ }^{32}$

In this work, we have examined four functionalized MIL$101 \mathrm{Cr}$ derivatives for the acid catalyzed conversion of glucose to 5-HMF using a THF/water system. For the first time, using a metal-organic framework catalyst a significant conversion of glucose to 5 -HMF of $29 \%$ has been achieved. In addition, the selectivity between the formation of 5-HMF and levulinic acid has been investigated and compared with sulfuric acid and Amberlyst-15 as catalysts.

\section{Experimental}

\section{Characterization of catalysts}

Powder X-ray diffraction (PXRD) patterns were recorded on a Bruker D2 phaser diffractometer in the Bragg-Brentano configuration with $\mathrm{Cu}-\mathrm{K} \alpha 1 / \alpha 2$ radiation $(\lambda=1.54184 \AA)$, a nickel filter and stationary flat-panel low background sample holder in the range $2 \theta=5-50^{\circ}$ (step width $0.02^{\circ}$ in $2 \theta$ ). Simulated powder patterns were based on single-crystal data and calculated using the STOE Win ${ }^{\text {XPOW }}$ software package ${ }^{33}$ or Mercury v. 3.3 software. ${ }^{34}$ Scanning electron microscopy (SEM) images were measured on a JSM6510 with an LaB6 cathode. The $\mathrm{N}_{2}$ sorption measurements were performed on a Quantachrome NOVA 4200e instrument at $77 \mathrm{~K}$. The samples were degassed under high vacuum $\left(10^{-5}\right.$ Torr $)$ at $150{ }^{\circ} \mathrm{C}$ for $3 \mathrm{~h}$, prior to each measurement. The BET surface area was calculated from adsorption isotherm data points in the pressure range $p / p_{0}=0.05-0.2$.

\section{Preparation of catalysts}

All MIL-101Cr materials were synthesized hydrothermally, utilizing an autoclave and programmable oven according to

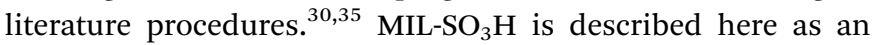
example: $\mathrm{CrO}_{3}(3.0 \mathrm{~g}, 30 \mathrm{mmol}), \mathrm{H}_{2} \mathrm{bdc}-\mathrm{SO}_{3} \mathrm{Na}(6.0 \mathrm{~g}, 30 \mathrm{mmol})$ and $12 \mathrm{~mol} \mathrm{~L}^{-1} \mathrm{HCl}(2.2 \mathrm{~g}, 60 \mathrm{mmol})$ were dissolved in $\mathrm{H}_{2} \mathrm{O}$ and split into four batches of $30 \mathrm{~mL}$, each of which was transferred into four Teflon-lined stainless steel autoclaves. The solutions were heated at $180{ }^{\circ} \mathrm{C}$ for 6 days (heating ramp $5 \mathrm{~h}$; cooling ramp $15 \mathrm{~h}$ ). For more details, see the ESI. $\dagger$

\section{Standard procedure for catalytic reactions}

In a typical experiment, the MIL-101 catalyst (50 mg) was suspended in a solvent mixture (39:1) of tetrahydrofuran (without stabilizer) $(4.875 \mathrm{~mL})$ and water $(125 \mu \mathrm{L})$ with a total volume of $5 \mathrm{~mL}$. The standard glucose loading was $5.0 \mathrm{wt} \%$ (223 $\mathrm{mg}, 1.24 \mathrm{mmol}$ ). The temperature was kept constant at $130{ }^{\circ} \mathrm{C}$ through a stirred oil bath around the reaction vial.
The reaction was stopped by cooling the reaction mixture to $0{ }^{\circ} \mathrm{C}$. The MIL catalysts were separated by centrifugation at $4800 \mathrm{rpm}$ for $10 \mathrm{~min}$ and the solution was passed through a syringe filter $(0.2 \mu \mathrm{m}$ diameter $)$.

Standard conditions: catalyst $5.22 \times 10^{-5} \mathrm{~mol}$, glucose $223 \mathrm{mg}$ (1.24 mmol), solvent $5 \mathrm{~mL}$ (THF: $\mathrm{H}_{2} \mathrm{O}$ (v:v) 39:1), $130{ }^{\circ} \mathrm{C}, 24 \mathrm{~h}$.

The concentrations of 5 -HMF in the organic THF phase were quantified by GC using external standard calibration $\left(R^{2}=0.9991, R=0.9995\right)$. For more details, see the ESI. $\dagger$

\section{Results and discussion}

\section{Synthesis and porosity of MOFs}

MIL-101Cr ${ }^{36}$ is a three-dimensional micro- to mesoporous material based on chromium-terephthalate linkages with the empirical formula $\left[\mathrm{Cr}_{3}(\mathrm{O}) \mathrm{X}(\mathrm{bdc})_{3}\left(\mathrm{H}_{2} \mathrm{O}\right)_{2}\right]$ (bdc $=$ benzene1,4-dicarboxylate, $\mathrm{X}=\mathrm{OH}$ or $\mathrm{F}$ depending on synthesis; here $\mathrm{X}=\mathrm{OH}) .{ }^{37} \mathrm{MIL}-101 \mathrm{Cr}$ has inner cages of $29 \AA$ and $34 \AA$ diameters with pore aperture windows of diameters up to $16 \AA$ (Fig. 3 and Fig. S1 in ESI $\dagger$ ). ${ }^{36}$ Two of the three Cr(III) octahedra in the trinuclear building unit have terminal aqua ligands, which can potentially be Lewis acid sites. ${ }^{38,39}$

MIL-101Cr and its linker-modified derivatives ${ }^{30,41}$ show remarkable stability towards water which make them most suitable for applications in the presence of moisture/water. ${ }^{29,30}$ In addition, 2-nitro and 2-sulfo-terephthalic acids were selected to compare the influence of different functional groups. The strong electron-withdrawing effect of 2-nitro-modified MIL-101Cr on the catalyst activity was already shown in the diacetalization of benzaldehyde. ${ }^{27}$ All modified MIL-101Cr materials were synthesized directly from the linker (2-nitro- or 2-sulfo-terephthalic acid) and $\mathrm{CrO}_{3}$ under acidic hydrothermal conditions (details are given in the ESI $\dagger){ }^{30,35}$ For mixed-linker MILs, a molar ratio of

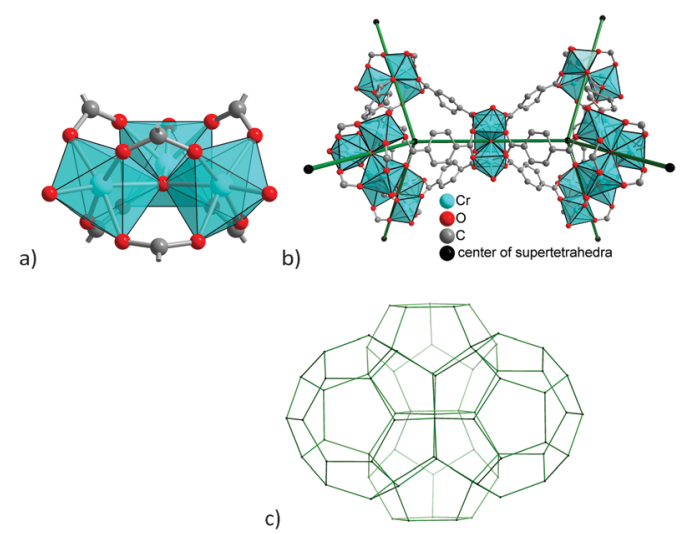

Fig. 3 (a) Trinuclear $\left\{\mathrm{Cr}_{3}\left(\mu_{3}-\mathrm{O}\right)(\mathrm{OH} / \mathrm{F})\left(\mathrm{H}_{2} \mathrm{O}\right)_{2}\left(\mathrm{O}_{2} \mathrm{C}-\right)_{6}\right\}$ building unit which is assembled by bridging benzene-1,4-dicarboxylate ligands into (b) vertexsharing supertetrahedra whose centers form the corners of (c) mesoporous cages with diameters of 29 or $34 \AA$ shown here in a zeolite-type framework presentation with the topological connectivity (in green) of the centers of the vertex-sharing supertetrahedra. Not-to-scale drawings (additional ones in Fig. S1, ESI $\dagger$ ) were generated from the deposited X-ray data file at the Cambridge Structure Database (CSD-Refcode OCUNAK) ${ }^{36}$ using the program DIAMOND. ${ }^{40}$ 
Table 1 Porous properties of MIL-X materials

\begin{tabular}{|c|c|c|c|c|c|}
\hline Materials & $\begin{array}{l}\text { BET surface area } \\
\left(\mathrm{m}^{2} \mathrm{~g}^{-1}\right)\end{array}$ & $\begin{array}{l}\text { Total pore volume } \\
\left(\mathrm{cm}^{3} \mathrm{~g}^{-1}\right)\end{array}$ & $\begin{array}{l}\text { Exp. ratio } \mathrm{NO}_{2}: \mathrm{SO}_{3} \mathrm{H} \\
\text { or bdc: } \mathrm{SO}_{3} \mathrm{H}^{c}\end{array}$ & $\begin{array}{l}\text { Number of Brønsted acid sites, } \\
\text { in formula unit }{ }^{d}\end{array}$ & $\begin{array}{l}\text { Particle diameter } \pm \text { standard } \\
\text { deviation }(\sigma)^{e}(\mathrm{~nm})\end{array}$ \\
\hline MIL-101Cr & 3049 & 1.50 & - & 2 & $174 \pm 35$ \\
\hline MIL-NO ${ }_{2}$ & 2058 & 1.18 & - & 2 & $168 \pm 30$ \\
\hline 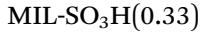 & 1633 & 0.93 & $2: 1$ & 2.99 & n.d. ${ }^{f}$ \\
\hline MIL-SO ${ }_{3} \mathrm{H}$ & 1333 & 0.70 & - & 5 & $152 \pm 43$ \\
\hline
\end{tabular}

${ }^{a}$ Calculated in the pressure range $0.05<p / p_{0}<0.2$ from $\mathrm{N}_{2}$ sorption isotherm at $77 \mathrm{~K}$. The BET error margin is $20-50 \mathrm{~m}^{2} \mathrm{~g}^{-1} \cdot{ }^{b} \mathrm{Calculated} \mathrm{from}^{2}$ $\mathrm{N}_{2}$ sorption isotherm at $77 \mathrm{~K}\left(p / p_{0}=0.95\right)$ for pores $\leq 40 \mathrm{~nm} .{ }^{c}$ Determined by digestion of MOF and ${ }^{1} \mathrm{H}-\mathrm{NMR}$ (see Fig. S2, ESI). ${ }^{d}$ From molecular formula based on the possible number of protic $\mathrm{H}$ atoms per formula unit (see ESI) of MIL $=\left[\mathrm{Cr}_{3}(\mathrm{O})(\mathrm{OH})(\mathrm{bdc}-\mathrm{X})_{3}\left(\mathrm{H}_{2} \mathrm{O}\right)_{2}\right]$. ${ }^{e} \mathrm{Obtained}$ from SEM measurements, minimum of 50 particles were counted. ${ }^{f}$ Particles are extremely agglomerated, particle size could not be determined (Fig. S3c, ESI).

$1: 1$ of the linkers $\mathrm{H}_{2}$ bdc $-\mathrm{NO}_{2} / \mathrm{H}_{2}$ bdc- $-\mathrm{SO}_{3} \mathrm{Na}$ and $\mathrm{H}_{2}$ bdc $/ \mathrm{H}_{2}$ bdc$\mathrm{SO}_{3} \mathrm{Na}$ was used in the synthesis. The effective linker ratio was then determined by digestive dissolution and ${ }^{1} \mathrm{H}$ NMR analysis (Table 1) (spectra in Fig. S2, ESI $\dagger$ ).

The MIL-101 structure of the linker-modified compounds was verified by positive matching of the simulated and measured powder X-ray diffractograms (Fig. S4, ESI $\dagger$ ). $\mathrm{N}_{2}$ sorption isotherms at $77 \mathrm{~K}$ showed the typical MIL-101 curvature with two steps up to $p / p_{0}=0.25$ in the otherwise Type Ib isotherm, characteristic of a wider microporous material (Fig. S5, ESI $\dagger$ ). ${ }^{42}$ BET surface areas and pore volumes were calculated from these $\mathrm{N}_{2}$ sorption isotherms. Among the four tested catalysts, $\mathrm{MIL}^{-\mathrm{NO}_{2}}$ $\left(2058 \mathrm{~m}^{2} \mathrm{~g}^{-1}\right)$ has the highest and MIL-SO $\mathrm{H}_{3} \mathrm{H}\left(1333 \mathrm{~m}^{2} \mathrm{~g}^{-1}\right)$ the lowest surface area. In our earlier contribution on the diacetal formation using MIL-101Cr derivatives, it could be shown that the surface area is not the decisive factor for high catalytic activity, but the particle size as well as electron withdrawing or donating functionalities has a higher influence on conversion. ${ }^{27}$

\section{Conversion of glucose to 5 -HMF}

Due to the high importance of platform chemicals derived from biomass, several solid acid catalysts have been investigated for the conversion of glucose to 5-HMF. ${ }^{19,28}$ Metal-organic frameworks were investigated for a number of acid-catalyzed reactions, ${ }^{43}$ including the conversion of fructose and glucose, albeit in a yield of maximum $16 \%$ for the latter. ${ }^{21}$ Therefore, this work focuses on the conversion of glucose to 5-HMF using MOF catalysts.

The conversion of glucose to 5-HMF was performed in the presence of each of the four functionalized MIL catalysts (Fig. 4) and the conversion was followed by gas chromatography (GC). In a typical experiment, $1.24 \mathrm{mmol}$ glucose $(223 \mathrm{mg})$ in $5 \mathrm{~mL}$ THF/water (v:v 39:1), ${ }^{10}$ giving a 5 wt $\%$ glucose solution, was heated in the presence of the catalyst $\left(5.22 \times 10^{-2} \mathrm{mmol}\right)$ for a chosen time at $130{ }^{\circ} \mathrm{C}$ in a Pyrex glass vial. For all experiments, $4.0 \mathrm{~mol} \%$ MIL catalyst with respect to glucose was used. In the literature, similar glucose or fructose substrate to MOFcatalyst ratios were used. ${ }^{20,21,25}$ When glucose was kept in THF/ water under the same conditions but in the absence of the MIL material, no formation of 5-HMF or any other products could be detected which shows that the MIL material is necessary for the catalytic reaction.

Comparing the catalytic activity of the four MIL-101Cr derivatives, the completely $\mathrm{SO}_{3} \mathrm{H}$-functionalized MIL has the

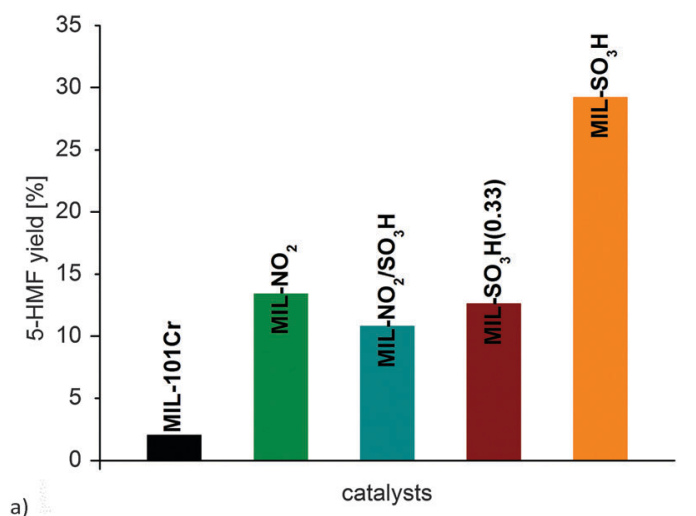

a)

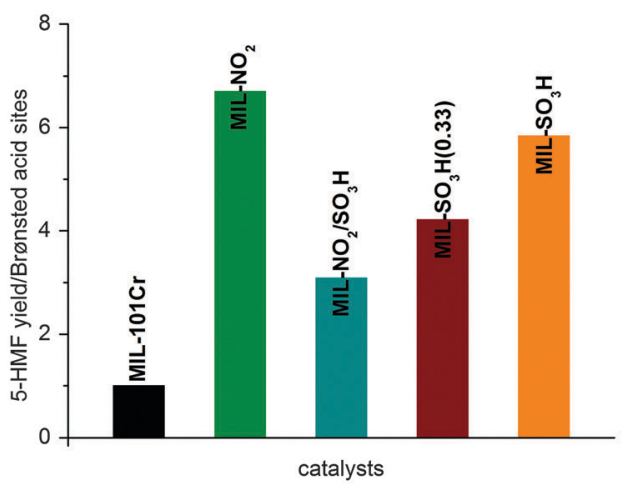

Fig. 4 (a) Conversion of glucose to 5-HMF with functionalized MIL-X (catalyst $5.22 \times 10^{-5} \mathrm{~mol}, 223 \mathrm{mg}$ glucose, $130{ }^{\circ} \mathrm{C}, 5 \mathrm{~mL} \mathrm{THF}: \mathrm{H}_{2} \mathrm{O}$ (v:v) $39: 1,24$ h). (b) Normalized to theoretical number of Brønsted acid (BA) sites (cf. Table 1)

highest activity. With $29 \%$ yield of 5-HMF (determined by calibrated GC after workup), this result is, to the best of our knowledge, the highest 5-HMF yield obtained using MOFs for the formation of 5-HMF from glucose. Interestingly, the other MOFs, MIL-NO ${ }_{2}, \mathrm{MIL}-\mathrm{SO}_{3} \mathrm{H}(0.33)$ and $\mathrm{MIL}-\mathrm{NO}_{2} / \mathrm{SO}_{3} \mathrm{H}$, give lower, but among them very similar, HMF yields of about $12-13 \%$. Pure MIL-101Cr shows a very low 5-HMF yield of only 2\% (standard conditions, $24 \mathrm{~h}$ ) (Fig. 4a). Interestingly, $\mathrm{MIL}^{-\mathrm{NO}_{2}}$, which has no obvious additional Brønsted acid sites compared to MIL-101Cr, shows a significantly higher 5-HMF yield, probably due to the stronger polarized aqua ligands through the electron-withdrawing nitro groups (Fig. 4a). Hence, the electron-withdrawing effect of 
the $\mathrm{NO}_{2}$ and additional acidic $\mathrm{SO}_{3} \mathrm{H}$ groups seems to have a strong influence on the catalytic activity of the MIL-101 platform. MIL-SO $\mathrm{S}_{3} \mathrm{H}$ gives the highest yield of 5-HMF and, therefore, this catalyst has been investigated in more detail.

If we assume that Brønsted acid (BA) catalysis takes place in the glucose to 5-HMF conversion and we normalize for the number of protons per formula unit ( $c f$. Table 1) the activity becomes highest for MIL-NO $\mathrm{N}_{2}$ with just two BA sites (Fig. 4b). We have tried to determine the number of accessible acidic sites by potentiometric titration according to literature procedures. ${ }^{44}$ Typically, MIL is stirred in a saturated solution of sodium chloride in order to exchange the protons with sodium. Our experiments revealed that MIL materials are not stable under these conditions (see $\mathrm{ESI} \dagger$ ), since two inflection points were observed although by the back-titration method only one acid strength $\left(\mathrm{HCl} / \mathrm{H}_{2} \mathrm{O}\right)$ should be present. We also followed a recently published approach by Klet and coworkers who used sodium nitrate for proton exchange (see ESI $\dagger$ ). ${ }^{45}$ Attempts to quantify the amount of available or accessible acid sites remained inconclusive (see ESI $\dagger$ ), which is why the theoretical number of acid sites was used (Table 1). We can only state from titration experiments that the amount of accessible protons is much smaller than what is calculated from the formula unit.

\section{Stability and recycling test}

In order to prove that no leaching occurs, $\mathrm{MIL}_{-} \mathrm{SO}_{3} \mathrm{H}$ was tested in a filtration experiment. The reaction was stopped by cooling to $0{ }^{\circ} \mathrm{C}$ after 5 hours and the catalyst was separated by centrifugation at $6000 \mathrm{rpm}$ and subsequent filtration of the filtrate using a $0.2 \mu \mathrm{m}$ syringe filter. The reaction was continued with the filtrate under identical conditions for different times, followed by the standard workup. No further formation of 5-HMF takes place over a period of 18:45 h (Table 2). Small differences of $1 \%$ were within experimental error of the reaction procedure, since for every measuring point a new reaction was started.

Multiple run experiments showed that $\mathrm{MIL}-\mathrm{SO}_{3} \mathrm{H}$ can be re-used up to 3-4 times with a loss in 5-HMF yield from $29 \%$ to $13-16 \%$ (Table $\mathrm{S} 3$ in the ESI $\dagger$ ). In a first series of recycle experiments, MIL-SO ${ }_{3} \mathrm{H}$ was re-used without any intermediate washing or reactivation steps. In the fourth run, the 5-HMF yield was reduced to $13 \%$. Therefore, the experiment was repeated such that after each run the catalyst was washed with water and methanol and dried before re-use. After three runs, a 5-HMF yield of $16 \%$ was measured. After three runs, the PXRD still

Table 2 Filtration experiment with $\mathrm{MIL}-\mathrm{SO}_{3} \mathrm{H}$

\begin{tabular}{lc}
\hline Time $(\mathrm{h})$ & Yield of $5-\mathrm{HMF}^{a}(\%)$ \\
\hline 5 (reaction was stopped) & 10 \\
10 & 9 \\
12 & 10 \\
14 & 12 \\
18.45 & 11
\end{tabular}

${ }^{a} \mathrm{MIL}_{-} \mathrm{SO}_{3} \mathrm{H} 5.22 \times 10^{-5} \mathrm{~mol}, 223 \mathrm{mg}$ glucose, $130{ }^{\circ} \mathrm{C}, 5 \mathrm{~mL}$ THF $: \mathrm{H}_{2} \mathrm{O}$ (v:v) $39: 1$; new batch was started for every entry at $t=0 \mathrm{~h}$.

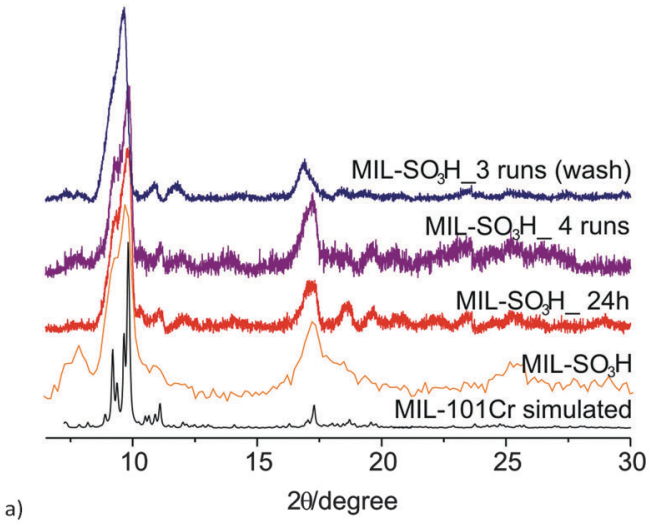

a)

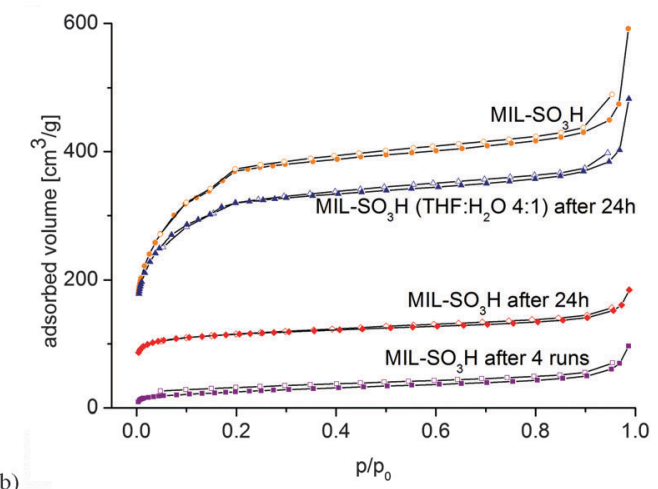

Fig. 5 (a) PXRD of MIL- $\mathrm{SO}_{3} \mathrm{H}$ before and after one catalytic run (24 h), 4 runs without washing, and after 3 runs with washing (see text) (standard conditions). (b) Nitrogen sorption isotherms (filled symbols for adsorption, empty symbols for desorption) of $\mathrm{MIL}-\mathrm{SO}_{3} \mathrm{H}$ before and after catalysis with one run (24 h), after one run ( $24 \mathrm{~h}$ ) using an additional $1 \mathrm{~mL}$ of $\mathrm{H}_{2} \mathrm{O}$ in the reaction and after 4 runs without washing. Standard conditions $\mathrm{MIL}-\mathrm{SO}_{3} \mathrm{H}$ $5.22 \times 10^{-5} \mathrm{~mol}, 223 \mathrm{mg}$ glucose, $130{ }^{\circ} \mathrm{C}, 5 \mathrm{~mL}$ THF : $\mathrm{H}_{2} \mathrm{O}$ (v:v) 39:1, except for $\mathrm{THF}: \mathrm{H}_{2} \mathrm{O}(\mathrm{v}: \mathrm{v}) \mathrm{4}: 1$.

shows crystalline $\mathrm{MIL}-\mathrm{SO}_{3} \mathrm{H}$ (Fig. 5a). The surface area was reduced to half after the first run $\left(443 \mathrm{~m}^{2} \mathrm{~g}^{-1}\right)$ and essentially lost after four runs $\left(91 \mathrm{~m}^{2} \mathrm{~g}^{-1}\right)$ (Fig. 5b). The surface area increased only negligibly from $91 \mathrm{~m}^{2} \mathrm{~g}^{-1}$ to $120 \mathrm{~m}^{2} \mathrm{~g}^{-1}$ after washing the MIL-SO ${ }_{3} \mathrm{H}$ material after the third run with $\mathrm{HCl}\left(2 \mathrm{~mol} \mathrm{~L}^{-1}\right)$ at $85{ }^{\circ} \mathrm{C}$ for $20 \mathrm{~h}$, followed by water and drying $\left(140{ }^{\circ} \mathrm{C}, 15 \mathrm{~h}\right)$.

\section{Effect of water content on 5-HMF yield}

It was suggested in a molecular simulation study that MIL$101 \mathrm{Cr}$ is able to adsorb glucose from an aqueous solution. ${ }^{46,47}$ Since the MIL material is known for its high uptake of water, ${ }^{29}$ this might be a driving force for glucose to diffuse into the pores, due to the much better solubility of glucose in water compared to THF.

In order to elucidate the effect of water on the conversion of glucose, the water content was increased gradually from 39:1 to $1: 1$. The results in Table 3 show that with increasing water content the yield of 5 -HMF becomes lower.

In pure water, only very low formation of 5-HMF was detected (6\%) and in pure THF no 5-HMF (and no other products) could be detected by GC. Therefore, a small amount of water is not only beneficial, but even necessary for 5-HMF formation. In this 
Table 3 Conversion of glucose to 5-HMF with different amounts of water

\begin{tabular}{ll}
\hline THF $:$ water ratio $^{a}(\mathrm{v}: \mathrm{v})$ & 5-HMF yield \\
& {$[\%]$} \\
\hline $39: 1$ & 29 \\
$9: 1$ & 24 \\
$4: 1$ & 13 \\
$2.3: 1$ & 7 \\
$1: 1$ & 5 \\
Pure $\mathrm{H}_{2} \mathrm{O}$ & 6 \\
Pure THF & 0 \\
${ }^{a}$ Conditions: $50 \mathrm{mg}$ MILL-SO & $\mathrm{H}, 5 \mathrm{wt} \%$ glucose, $5 \mathrm{~mL}$ solvent, $24 \mathrm{~h}$, \\
$130{ }^{\circ} \mathrm{C} .{ }^{b}$ Determined by GC. &
\end{tabular}

respect, our reaction system differs significantly from the sulfuric acid study of Huber and coworkers, since for conc. (water-free) $\mathrm{H}_{2} \mathrm{SO}_{4}$ also in water-free THF, the formation of 5-HMF was detected. ${ }^{10}$ A possible explanation might be that the development of full acid strength of the MOF catalyst involves the polarization of water at the chromium centers of the MOFs. Glucose is more soluble in water than in THF. When water is adsorbed by the MIL catalyst this might be the driving force resulting in a higher 5-HMF yield, at low amounts of water, having a higher local concentration of glucose in the MIL environment. The glucose concentration in the MOF vicinity would be lowered further with too much or only water as solvent. In addition, THF is known to stabilize 5-HMF and prevent the formation of levulinic acid. ${ }^{48}$ Abu-Omar et al. showed that by using $\mathrm{NaCl}$ in a $\mathrm{THF} / \mathrm{H}_{2} \mathrm{O}$ mixture as a phase separator, the 5 -HMF yield from glucose could be increased from $52 \%$ to $61 \%$ in comparison to the system without $\mathrm{NaCl}$ (catalyst $\mathrm{AlCl}_{3}$, $\mathrm{HCl}, 160{ }^{\circ} \mathrm{C}$ ). Since the reaction takes place in water a good phase separation and a good continuous transfer of 5-HMF to the organic THF phase is necessary. ${ }^{48}$ In the case of MIL-SO $\mathrm{S}_{3} \mathrm{H}$ catalysis in THF: $\mathrm{H}_{2} \mathrm{O}(\mathrm{v}: \mathrm{v} 39: 1)$, these requirements are apparently fulfilled best.

\section{Formation of humins and deactivation pathways}

The degradation of carbohydrates to humins plays a crucial role in glucose conversion and catalyst degradation. This kind of deactivation can be classified as fouling. ${ }^{49}$ The formation of humins is not well investigated. Generally, unidentified soluble or insoluble degradation products are called humins. ${ }^{6 b, d, 50}$ Recently, Vlachos et al. investigated the effect of reaction conditions, 5-HMF conversion and acid concentration on the molecular structure and formation of humins, using FTIR spectroscopy, SEM and in-situ dynamic light scattering (DLS). ${ }^{51}$ It was concluded that combined effects of aldol condensation and etherification reactions as well as nucleophilic attack from 5-HMF and aggregation effects lead to insoluble polymers, especially at high 5 -HMF yield. ${ }^{51}$ These by-products can block the pores so that no substrate can migrate in and no product can form or migrate out anymore. If the degradation products are also formed inside the pores, they block the MOF pores, which leads to deactivation.

With increasing amount of water in the reaction solvent the yield of 5-HMF became lower (see Table 3). Yet, with increasing water fraction also less insoluble humin products are formed as
Table 4 Product distribution in different solvent mixtures

\begin{tabular}{|c|c|c|c|}
\hline \multirow[b]{2}{*}{$\begin{array}{l}\text { Solvent } \\
\text { mixture } \\
(\mathrm{v}: \mathrm{v})\end{array}$} & $\begin{array}{l}\text { 5-HMF } \\
\text { yield }^{b}[\%]\end{array}$ & $\begin{array}{l}\text { 5-Ethyl-HMF } \\
\text { yield }^{b}[\%]\end{array}$ & \multirow[b]{2}{*}{$\begin{array}{l}\text { MIL-SO } \mathrm{SO}_{3} \mathrm{H} \text { surface } \\
\text { area } S_{\mathrm{BET}}\left[\mathrm{m}^{2} \mathrm{~g}^{-1}\right] \\
\text { after reaction }\end{array}$} \\
\hline & & & \\
\hline $\mathrm{THF} / \mathrm{H}_{2} \mathrm{O}(39: 1)$ & 29 & 0 & 443 \\
\hline $\begin{array}{l}\mathrm{THF} / \mathrm{EtOH} / \mathrm{H}_{2} \mathrm{O} \\
(23: 16: 1)\end{array}$ & 13 & 7 & 1028 \\
\hline $\mathrm{EtOH} / \mathrm{H}_{2} \mathrm{O}(39: 1)$ & 5 & 11 & 1239 \\
\hline
\end{tabular}

evidenced from the color retention of the MIL and weight of the solid materials after the reaction (Fig. S6 and Table S2 in the ESI $\dagger$ ). To determine the amount of insoluble humins which have formed, the solid material was separated by centrifugation and dried $\left(120^{\circ} \mathrm{C}\right.$, overnight). The weights are listed in Table S2 (ESI†). Also, with increasing water fraction the BET surface area of MIL- $\mathrm{SO}_{3} \mathrm{H}$ is diminished less after one catalytic run (Fig. $5 \mathrm{~b}$ ). When the catalytic reaction was carried out in a THF/water mixture of $4: 1$, the MIL- $\mathrm{SO}_{3} \mathrm{H}$ catalyst still had a BET surface area of $1161 \mathrm{~m}^{2} \mathrm{~g}^{-1}$ after the first run.

Regeneration attempts were performed by washing the catalyst after the reaction with methanol, THF and $\mathrm{H}_{2} \mathrm{O}$ as well as acid $\left(\mathrm{H}_{2} \mathrm{SO}_{4}\right)$ at room temperature and at $80{ }^{\circ} \mathrm{C}$. No significant improvement of the surface area was measured. Since regeneration attempts failed and calcination is not possible due to instability of the MOF above $350^{\circ} \mathrm{C}$, the most effective way would be to prevent the formation of humins during the catalytic reaction.

A possible strategy to inhibit the formation of insoluble humins may be to deactivate the polymerizable sites of 5-HMF. Therefore, experiments were performed using ethanol in a mixture with THF and water (Table 4). Also in the presence of ethanol, the formation of 5-ethoxymethylfurfural (5-ethyl-HMF) was observed in addition to 5-HMF. The higher the amount of ethanol the higher was the yield of 5-ethyl-HMF.

The amount of insoluble humins seemed to be reduced when the reaction was carried out in ethanol $/ \mathrm{H}_{2} \mathrm{O}$, evidenced by the retention of the MIL porosity, its color and the amount of the catalyst (Fig. S6, S7 and Table S2 in ESI $\dagger$ ). Unfortunately, in $\mathrm{EtOH} / \mathrm{H}_{2} \mathrm{O}$ the overall yield and product selectivity are much lower than in the THF: $\mathrm{H}_{2} \mathrm{O}(\mathrm{v}: \mathrm{v} 39: 1)$ mixture (Table 4).

\section{Time profile}

The yield of 5-HMF slowly approaches the determined value over the maximum allowed reaction time of $24 \mathrm{~h}$ under our standard conditions (Fig. 6). The space--time yield is much lower than with other catalysts such as sulfuric acid, ${ }^{10} \mathrm{AlCl}_{3},{ }^{52}$ montmorillonite K-10 clay ${ }^{53}$ or beta zeolites, ${ }^{54}$ where saturation is observed within $40 \mathrm{~min}$ to $5 \mathrm{~h}$. This difference in the reaction rate can give a hint on the reaction mechanism, since it was suggested with homogeneous $\mathrm{AlCl}_{3} / \mathrm{solvent} / \mathrm{H}_{2} \mathrm{O}$ that the catalysis proceeds by glucose to fructose isomerization (Lewis acid catalyzed) and subsequent dehydration to 5-HMF. This reaction route 


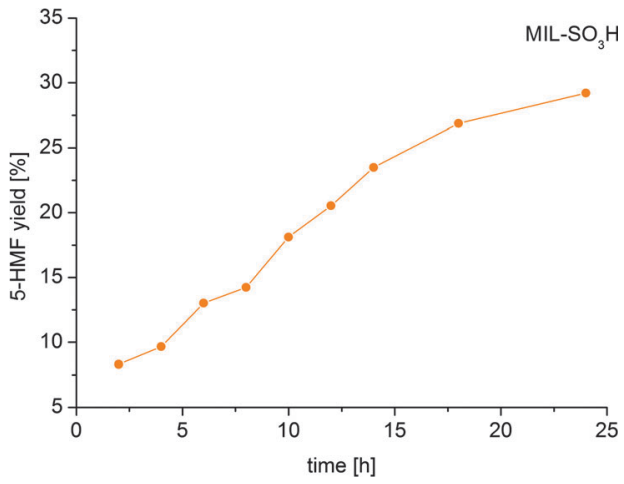

Fig. 6 Time dependent conversion of glucose to 5-HMF. Standard conditions: catalyst $50 \mathrm{mg}$, glucose $223 \mathrm{mg}, 5 \mathrm{~mL}$ THF: $\mathrm{H}_{2} \mathrm{O}$ (v:v) $39: 1,130{ }^{\circ} \mathrm{C}$.

seems to be much faster than only Brønsted acid catalyzed conversion by homogeneous sulfuric acid. ${ }^{11,55}$

Glucose signals were still detected after 8 and $15 \mathrm{~h}$ when the reaction was stopped by cooling after 8,15 and $24 \mathrm{~h}$ and analyzed by NMR in $\mathrm{D}_{2} \mathrm{O}$ (Fig. S9, ESI $\dagger$ ). After $24 \mathrm{~h}$, saccharide signals were not seen any more in the NMR spectrum (Fig. 9).

Assuming that the conversion of glucose takes place inside the pores or at least in the pore mouths of the MOF, diffusion limitations can be the reason for the slow conversion.

When decreasing the temperature to $100{ }^{\circ} \mathrm{C}$ under standard conditions the formation of 5-HMF is even slower; after $24 \mathrm{~h}$ only $8 \%$ can be detected. At $100{ }^{\circ} \mathrm{C}$, only the formation of 5-HMF and the starting material is visible from the NMR spectrum (in $\mathrm{D}_{2} \mathrm{O}$ ); no by-products are formed (Fig. S8d, ESI $\dagger$ ).

\section{Conversion of other substrates to 5-HMF}

The reaction of maltose $(5 \mathrm{wt} \%, 0.65 \mathrm{mmol})$ with MIL- $\mathrm{SO}_{3} \mathrm{H}$ resulted in a conversion of $50 \%$ to 5 -HMF. Maltose is a glucosedimer with the two monomer units connected through a glycosylbond. The same mass of maltose contains almost the same amount of glucose monomer units as in $223 \mathrm{mg}$ glucose used under our standard conditions. Since the 5-HMF yield from maltose is higher than from glucose, it seems that the (unknown) intermediate state is more easily accessible from the dimer maltose. Also, the possible intermediates levoglucosan and fructose were used as starting materials and the reaction was performed under standard conditions $\left(50 \mathrm{mg}\right.$ MIL- $\mathrm{SO}_{3} \mathrm{H}, 1.24 \mathrm{mmol}$ sugar, THF $: \mathrm{H}_{2} \mathrm{O}$ (v:v) $39: 1,130^{\circ} \mathrm{C}$ ). With levoglucosan after $8 \mathrm{~h}$ a 5 -HMF yield of $12 \%$ and after $24 \mathrm{~h}$ of $28 \%$ was measured by GC. It is evident that 5-HMF can be formed also from levoglucosan, but only to a similar extent as from glucose.

It has already been shown by several groups that fructose can be converted to 5-HMF in good yields by Brønsted acidic MOF materials in other solvents. ${ }^{20,25}$ In our study, a maximum yield of 5-HMF of $47 \%$ was obtained after $8 \mathrm{~h}$ under standard conditions. As expected, the conversion of fructose proceeds much faster than the conversion of glucose. The formation of humins was also observed with fructose, levoglucosan and maltose by color and weight change.

Cellulose with MIL-SO ${ }_{3} \mathrm{H}$ shows almost no formation of 5-HMF (1\%). This could indicate that the long polymer chains of cellulose cannot enter the pores of $\mathrm{MIL}-\mathrm{SO}_{3} \mathrm{H}$ for conversion or, alternatively, that the chains are not cleaved to a sufficient extent.

\section{Formation of 5-HMF versus levulinic acid}

When 5-HMF is dissolved in THF/water ( $\mathrm{v}: \mathrm{v} 39: 1)$ and reacted at $130{ }^{\circ} \mathrm{C}$ for $24 \mathrm{~h}$ with the catalyst MIL-SO $\mathrm{S}_{3} \mathrm{H}$, no reaction is observed; only the starting material 5-HMF can be detected by GC or GC-MS. The ${ }^{1} \mathrm{H}$ NMR spectrum of the reaction solution (without workup) showed only trace amounts of levulinic acid (molar ratio 5-HMF to levulinic acid, 1: 0.04). The catalyst also retained its green color instead of changing to brown, which indicates no formation of humins as in the glucose conversion. In contrast, Dumesic and coworkers showed that other catalysts, for instance, $\mathrm{H}_{2} \mathrm{SO}_{4}$, Amberlyst-70 or zeolites will give levulinic acid from furfuryl alcohol in $\mathrm{THF} / \mathrm{H}_{2} \mathrm{O}$ solutions with levulinic acid yields of over $70 \% .^{57}$

The selectivity of the glucose-to-5-HMF conversion concerning the formation of levulinic acid as a by-product was analyzed by NMR. Since levulinic acid is very soluble in water, the complete reaction solution was dried in vacuum; the residue was re-dissolved in deuterated solvent and then measured. All reactions have been performed under standard conditions for $24 \mathrm{~h}$, unless stated otherwise.

With MIL-SO ${ }_{3} \mathrm{H}$ and glucose, the selectivity towards 5-HMF over levulinic acid is $80 \%$, since the molar ratio between 5 -HMF and levulinic acid is 1 to 0.25 after $24 \mathrm{~h}$ (Table 5 and Fig. 7).

Table 5 Time dependent analysis of reaction mixture by NMR ${ }^{a}$

\begin{tabular}{lll}
\hline Time (h) & $\begin{array}{l}\text { Integral ratio 5-HMF vs. } \\
\text { levulinic acid }\end{array}$ & $\begin{array}{l}\text { Selectivity of 5-HMF over } \\
\text { levulinic acid (\%) }\end{array}$ \\
\hline 8 & $1: 0.13$ & 88 \\
15 & $1: 0.16$ & 86 \\
24 & $1: 0.25$ & 80 \\
$24 \mathrm{~h}^{b}$ & $1: 0.09$ & 92 \\
$24 \mathrm{~h}^{c}$ & $1: 0.21$ & 83
\end{tabular}

${ }^{a}$ Conditions: $50 \mathrm{mg}$ MIIL-SO $\mathrm{S}_{3} \mathrm{H}, 5 \mathrm{wt} \%$ glucose, $5 \mathrm{~mL}$ THF $: \mathrm{H}_{2} \mathrm{O}(\mathrm{v}: \mathrm{v})$ $39: 1,130{ }^{\circ} \mathrm{C}$. Determined by ${ }^{1} \mathrm{H}-\mathrm{NMR}$ in $\mathrm{D}_{2} \mathrm{O} .{ }^{b}$ Fructose as substrate $(1.24 \mathrm{mmol}) .{ }^{c}$ Levuglucosan as substrate $(1.24 \mathrm{mmol}) .{ }^{d}$ Integral ratio of $\mathrm{CH}_{2}$ groups: $\mathrm{D}(5-\mathrm{HMF})$ and the average of the $\mathrm{E}$ and $\mathrm{F}$ signal (levulinic acid), see Fig. 9.

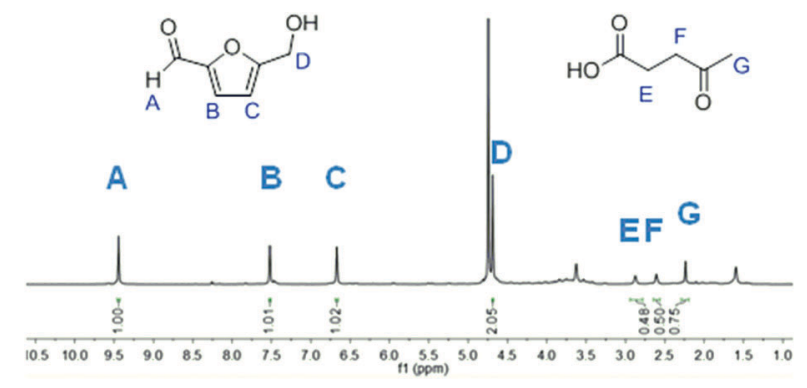

Fig. $7{ }^{1} \mathrm{H}$ NMR spectrum of the soluble reaction products from glucose (50 mg MIL-SO ${ }_{3} \mathrm{H}, 223 \mathrm{mg}$ glucose, $5 \mathrm{~mL}$ THF : $\mathrm{H}_{2} \mathrm{O}$ (v: v) $39: 1,130{ }^{\circ} \mathrm{C}$, $24 \mathrm{~h}$ ) (NMR solvent $\mathrm{D}_{2} \mathrm{O}$ ). The 5-HMF to levulinic acid ratio was based on the integral ratio of the $\mathrm{CH}_{2}$ groups, that is, the $\mathrm{D}$ and the average of the $\mathrm{E}$ and $\mathrm{F}$ signals. 
After $8 \mathrm{~h}$ and $15 \mathrm{~h}$ reaction times, the selectivity towards 5 -HMF over levulinic acid is even higher $(88 \%$ and $86 \%$, respectively) and decreases with time (Table 5 and Fig. S9, ESI $\dagger$ ). This indicates that 5-HMF also slowly converts to levulinic acid. As pure 5-HMF with MIL-SO $\mathrm{S}_{3} \mathrm{H}$ shows only a very low conversion over $24 \mathrm{~h}$ (see above) other reaction products may assist in this conversion.

For comparison, MIL-SO $\mathrm{SO}_{3} \mathrm{H}$ was also reacted with levoglucosan $(1.24 \mathrm{mmol})$ and fructose $(1.24 \mathrm{mmol})$ as substrate and similar ratios between 5-HMF and levulinic acid were obtained (Fig. S8a, b, ESI $\dagger$ and Table 5). Interestingly, the ${ }^{1} \mathrm{H}$ NMR spectrum of the glucose conversion with $\mathrm{MIL}-\mathrm{NO}_{2}$ shows signals of $5-\mathrm{HMF}$, but no levulinic acid is found. Only some signals of unidentified products can be found (Fig. S8c, ESI $\dagger$ ). In summary, $\mathrm{MIL}_{-} \mathrm{SO}_{3} \mathrm{H}$ shows the highest yield of 5-HMF which correlates with the highest potential number of acid sites of the MIL-materials (Fig. 4), whereas MIL-NO $\mathrm{N}_{2}$ shows a very selective formation of 5-HMF since no levulinic acid was found.

For comparison, chromium(III) nitrate, sulfuric acid and Amberlyst-15 have been tested as catalysts $\left(1.57 \times 10^{-4} \mathrm{~mol}\right)$ for the formation of 5-HMF under the same conditions as the MIL-materials (THF : $\mathrm{H}_{2} \mathrm{O}$ (v:v) $39: 1,130{ }^{\circ} \mathrm{C}, 223 \mathrm{mg}$ glucose) for $24 \mathrm{~h} . \mathrm{CrCl}_{3}$ is known to catalyze the isomerization from glucose to fructose. Also, the formation of 5-HMF, levulinic acid and formic acid was observed with $\mathrm{CrCl}_{3}{ }^{7 a, 56}$ In contrast to MIL-SO ${ }_{3} \mathrm{H}$, the yield of 5-HMF from glucose catalyzed by $\mathrm{Cr}\left(\mathrm{NO}_{3}\right)_{3}$ is only $6 \%$ after $24 \mathrm{~h}$. Interestingly, no levulinic acid was detected, but a high amount of unidentified products can be observed by NMR and GC-MS. The high formation of by-products in the case of $\mathrm{Cr}^{3+}$ salts is supported by a comprehensive study of Vlachos et al. ${ }^{7 a}$

Comparing the product distribution using $\mathrm{MIL}-\mathrm{SO}_{3} \mathrm{H}$ as a catalyst or $\mathrm{H}_{2} \mathrm{SO}_{4}$ as a homogenous catalyst or the strong acidic resin Amberlyst-15, starting from glucose, a significant change can be observed (Fig. 8 and Fig. S10, ESI $\dagger$ ). For Amberlyst-15,

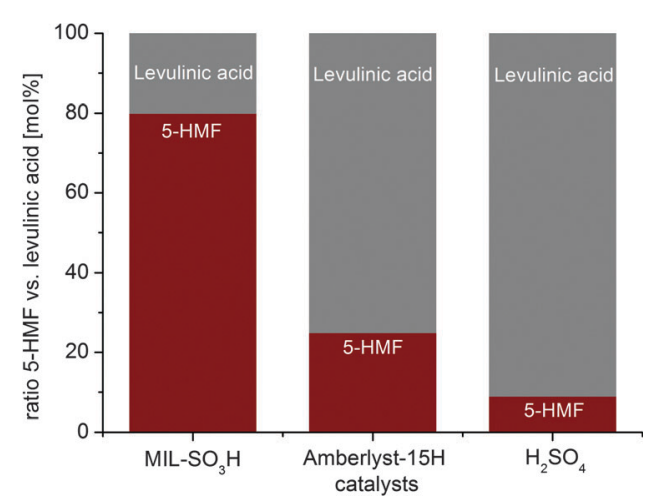

Fig. 8 Ratio between 5-HMF and levulinic acid from ${ }^{1} \mathrm{H}-\mathrm{NMR}$. Comparison between MIL-SO ${ }_{3} \mathrm{H}, \mathrm{H}_{2} \mathrm{SO}_{4}$ and Amberlyst- $15 \mathrm{H}$. Conditions: catalyst MIL- $\mathrm{SO}_{3} \mathrm{H} 5.22 \times 10^{-5} \mathrm{~mol}$, glucose $223 \mathrm{mg}, 5 \mathrm{mLTHF}: \mathrm{H}_{2} \mathrm{O}$ (v:v) $39: 1$, $130{ }^{\circ} \mathrm{C}$. For $\mathrm{H}_{2} \mathrm{SO}_{4}$ and Amberlyst-15 the reaction was conducted with $1.57 \times 10^{-4} \mathrm{~mol}$ of the catalyst under the same conditions. The estimated amount of acid of MIL-SO ${ }_{3} \mathrm{H}$, Amberlyst-15 and sulfuric acid is $0.46 \mathrm{mmol}$ $\mathrm{H}^{+}$per $\mathrm{g}$ (see Table S4, ESI $\dagger$ ), $4.7 \mathrm{mmol} \mathrm{H}^{+}$per g (AMBERLYST ${ }^{\mathrm{TM}}$ product information) and $10.2 \mathrm{mmol} \mathrm{H}^{+}$per $\mathrm{g}$, respectively. the selectivity is strongly directed to levulinic acid, with a $1: 3$ ratio of 5-HMF to levulinic acid (5-HMF selectivity only $25 \%$ ). For sulfuric acid as a catalyst the major dominant product is also levulinic acid. The ratio between 5-HMF and levulinic acid is $1: 10$ (5-HMF selectivity $9 \%$ ).

Recently, Dumesic et al. reported the conversion of furfuryl alcohol into levulinic acid using different solid acids (including Amberlyst-70 and H-ZSM-5) as well as sulfuric acid in a similar THF/water system. ${ }^{57}$ Huber et al. reported the formation of levulinic acid as a by-product from glucose conversion to 5-HMF using sulfuric acid (catalyst). ${ }^{10}$

It is evident that the ratio of 5-HMF to levulinic acid is inversely proportional to the acidity of the catalyst. The significantly lower actual acidity of $\mathrm{MIL}-\mathrm{SO}_{3} \mathrm{H}$ compared to Amberlyst-15 and $\mathrm{H}_{2} \mathrm{SO}_{4}$ explains the low-high ratio of 5-HMF to levulinic acid. The even lower acidity of MIL-NO $\mathrm{N}_{2}$ then explains the absence of levulinic acid. At present, it is not fully clear if 5 -HMF is converted to levulinic acid. Levulinic acid could also form through a 5-HMF independent pathway (see the Mechanistic aspects section in the ESI $\dagger){ }^{11}$

The 5-HMF yield varies only slightly, essentially within experimental error, with the amount of $\mathrm{MIL}-\mathrm{SO}_{3} \mathrm{H}$ catalyst (Fig. 9).

Increasing the ratio of $\mathrm{MIL}-\mathrm{SO}_{3} \mathrm{H}$ to glucose from the standard 1: 7.9 (223 $\mathrm{mg}$ glucose) to 1:3.5 (100 mg glucose) gives a 5 -HMF yield of $34 \%$ (up from $29 \%$ ). By decreasing the ratio of MIL-SO ${ }_{3} \mathrm{H} /$ glucose to $1: 17.7$ (500 mg), a slight decrease in 5-HMF formation to $26 \%$ can be observed (Fig. 9). These results show that the catalyst remains active even at higher concentrations of glucose and the percentage yield does not change significantly with a moderate variation of the substrate ratio.

Parallel to this work, Su and coworkers also investigated the activity of $\mathrm{MIL}-101 \mathrm{Cr}-\mathrm{SO}_{3} \mathrm{H}$ on the glucose to $5-\mathrm{HMF}$ conversion. $^{58}$ They used a solvent mixture of $\gamma$-valerolactone (GVL) and $\mathrm{H}_{2} \mathrm{O}(9: 1)$ at $150{ }^{\circ} \mathrm{C}$. The glucose to catalyst ratio can be calculated as 1:5 or $1: 2$ (considering $3 \mathrm{Cr}$ ions per formula unit), taking into account that only $60 \%$ of the linker had a $\mathrm{SO}_{3} \mathrm{H}$ moiety. In our study, the glucose to $\mathrm{MIL}-\mathrm{SO}_{3} \mathrm{H}$ ratio was $1: 24$ or $1: 8$. Su et al. ${ }^{58}$ synthesized MIL-101Cr- $\mathrm{SO}_{3} \mathrm{H}$ from monosodium sulfoterephthalic acid, $\mathrm{HF}$ and $\mathrm{Cr}\left(\mathrm{NO}_{3}\right)_{3}$ instead

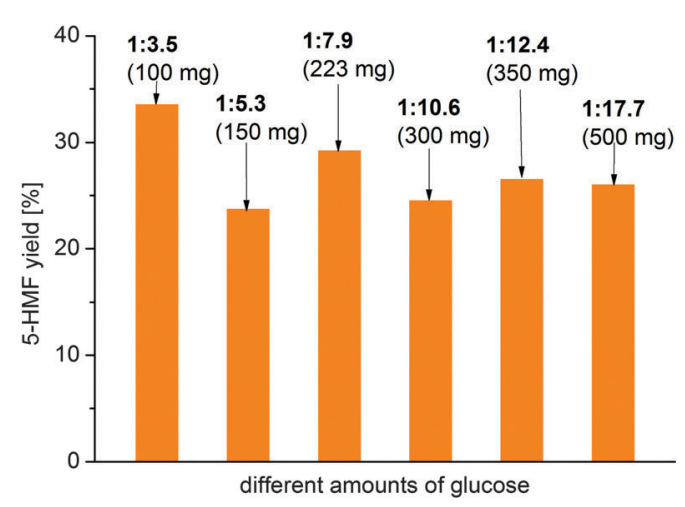

Fig. 9 Conversion of glucose to 5-HMF with different amounts of glucose and MIL-SO ${ }_{3} \mathrm{H}$ as catalyst (given is the molar $\mathrm{Cr}(\mathrm{III})\left(1.57 \times 10^{-4} \mathrm{~mol}\right)$ ) to glucose ratio (catalyst $5.22 \times 10^{-5} \mathrm{~mol}, 130{ }^{\circ} \mathrm{C}, 5 \mathrm{~mL} \mathrm{THF} \mathrm{:} \mathrm{H}_{2} \mathrm{O}$ (v: v) $39: 1,24 \mathrm{~h}$ ). 
of $\mathrm{CrO}_{3}$. The average particle size of $\mathrm{MIL}-101 \mathrm{Cr}-\mathrm{SO}_{3} \mathrm{H}$ was higher with $400 \mathrm{~nm}$ and the BET surface area was $1700 \mathrm{~m}^{2} \mathrm{~g}^{-1}$. Under their reported conditions, a highest 5-HMF yield of $45 \%$ and selectivity of $46 \%$ could be achieved. Acidity was calculated from back-titration experiments with saturated $\mathrm{NaCl}$ to $1.61 \mathrm{mmol} \mathrm{g}^{-1}$. Unfortunately, no titration curves were given. ${ }^{58}$

It was shown that the high boiling solvent GVL is beneficial for the 5-HMF yield over short reaction times $(2 \mathrm{~h})$. Similar to our work, lower 5-HMF yields were also found for higher amounts of water. In contrast, in pure GVL also 26\% 5-HMF yield was obtained, ${ }^{58}$ whereas in our study no conversion was observed in pure THF. In terms of the mechanism, the authors referred to the 1,2-hydride shift, proven for Lewis acidic zeolites. Through HPLC experiments small amounts of fructose could be identified, although the possibilities of alternative intermediates are not discussed. They suggest a second order kinetics for the reaction. In fixed bed reactions, a 5-HMF yield between 35 and $45 \%$ over 56 h was obtained. ${ }^{58}$

The scope of using MOFs as catalysts in the synthesis of fine chemicals is summarized elsewhere, ${ }^{16,59}$ but the advantage of selective catalysis in 5 -HMF formation is obvious. Synergistic effects due to reactions catalyzed in confined space are highlighted in the literature ${ }^{60}$ and could be an important factor explaining the selectivity towards 5-HMF using MILs as catalysts. A defined solvent microenvironment due to the preferred uptake of water by the MIL catalyst can also play a role.

\section{Conclusions}

For different nitro- and sulfo-modified MIL-101Cr compounds, MIL-SO ${ }_{3} \mathrm{H}$ gives the highest yield of 5-HMF from glucose of $29 \%$ after $24 \mathrm{~h}$. This yield is lower than the results obtained using other solid acid catalysts, ${ }^{28}$ but at present the highest value is reported for the glucose-to-5-HMF conversion catalyzed by metalorganic frameworks. Importantly, it could be shown that the reaction only proceeds with a small amount of water. In pure THF, no product formation was observed. Furthermore, also from pure 5-HMF as a reactant, only very little production of levulinic acid could be detected, in contrast to the results in the literature using sulfuric acid ${ }^{10}$ or Amberlyst-70. ${ }^{57}$ Under the same conditions, MIL-SO ${ }_{3} \mathrm{H}$, sulfuric acid and Amberlyst-15 show significantly different $5-\mathrm{HMF} /$ levulinic acid product distributions. MIL-SO ${ }_{3} \mathrm{H}$ preferentially forms 5 -HMF over levulinic acid in contrast to the other catalysts. Reactivation of the MOF catalyst remains a challenge, since pore blocking effects have been observed in multiple run experiments. Derivatisation to 5-ethylHMF is a promising way, avoiding the formation of insoluble humins. At present, the 5-ethyl-HMF yield is low, awaiting the development of more active MOF-based acidic catalysts.

\section{Acknowledgements}

The work was funded in part by the Deutscher Akademischer Austauschdienst, DAAD, through PPP-project no. 57053987 (China $2 \mathrm{j}$ ab 14).

\section{References}

1 (a) P. Gallezot, Chem. Soc. Rev., 2012, 41, 1538-1558; (b) S. Dutta and S. Pal, Biomass Bioenergy, 2014, 62, 182-197.

2 C. Chatterjee, F. Pong and A. Sen, Green Chem., 2015, 17, 40-71.

3 (a) A. A. Koutinas, A. Vlysidis, D. Pleissner, N. Kopsahelis, I. L. Garcia, I. K. Kookos, S. Papanikolaou, T. H. Kwan and C. S. K. Lin, Chem. Soc. Rev., 2014, 43, 2587-2627; (b) D. Esposito and M. Antonietti, Chem. Soc. Rev., 2015, 44, 5821-5835.

4 T. Wang, M. W. Nolte and B. H. Shanks, Green Chem., 2014, 16, 548-572.

5 R. Beerthuis, G. Rothenberg and N. R. Shiju, Green Chem., 2015, 17, 1341-1361.

6 (a) B. Saha and M. M. Abu-Omar, Green Chem., 2014, 16, 24-38; (b) R. van Putten, J. C. van der Waal, E. de Jong, C. B. Rasrendra, H. J. Heeres and J. G. de Vries, Chem. Rev., 2013, 113, 1499-1597; (c) S. P. Teong, G. Yi and Y. Zhang, Green Chem., 2014, 16, 2015-2026; (d) A. A. Rosatella, S. P. Simeonov, R. F. M. Frade and C. A. M. Afonso, Green Chem., 2011, 13, 754-793.

7 (a) V. Choudhary, S. H. Mushrif, C. Ho, A. Anderko, V. Nikolakis, N. S. Marinkovic, A. I. Frenkel, S. I. Sandler and D. G. Vlachos, J. Am. Chem. Soc., 2013, 135, 3997-4006; (b) J. Tang, X. Guo, L. Zhu and C. Hu, ACS Catal., 2015, 5, 5097-5103.

8 C. Liu, J. M. Carraher, J. L. Swedberg, C. R. Herndon, C. N. Fleitman and J. Tessonnier, ACS Catal., 2014, 4, 4295-4298.

9 J. M. Carraher, C. N. Fleitman and J. Tessonnier, ACS Catal., 2015, 5, 3162-3173.

10 R. Weingarten, A. Rodriguez-Beuerman, F. Cao, J. S. Luterbacher, D. Martin Alonso, J. A. Dumesic and G. W. Huber, ChemCatChem, 2014, 6, 2229-2234.

11 L. Yang, G. Tsilomelekis, S. Caratzoulas and D. G. Vlachos, ChemSusChem, 2015, 8, 1334-1341.

12 R. A. Sheldon, Chem. Commun., 2008, 3352-3365.

13 P. Wasserscheid and T. Welton, Ionic Liquid in Synthesis, Wiley-VCH, Weinheim, 2007, vol. 1, pp. 325-350.

14 P. Wasserscheid and W. Keim, Angew. Chem., Int. Ed., 2000, 39, 3773-3789 (Angew. Chem., 2000, 112, 3926-3945).

15 C. van Doorslaer, Y. Schellekens, P. Mertens, K. Binnemanns and D. De Vos, Phys. Chem. Chem. Phys., 2010, 12, 1741-1749.

16 P. Garcia-Garcia, M. Müller and A. Corma, Chem. Sci., 2014, 5, 2979-3007.

17 J. Gascon, A. Corma, F. Kapteijn and F. X. Llabres i Xamena, ACS Catal., 2014, 4, 361-378.

18 (a) F. Vermoortele, M. Vandichel, B. Van de Voorde, R. Ameloot, M. Waroquier, V. Van Speybroeck and D. E. De Vos, Angew. Chem., Int. Ed., 2012, 51, 4887-4890; (b) P. Valvekens, F. Vermoortele and D. De Vos, Catal. Sci. Technol., 2013, 3, 1435-1445.

19 J. Jiang and O. M. Yaghi, Chem. Rev., 2015, 115, 6966-6997. 20 Y. Zhang, V. Degirmenci, C. Li and E. J. M. Hensen, ChemSusChem, 2011, 4, 59-64.

21 L. Bromberg, X. Su and T. A. Hatton, Chem. Mater., 2014, 26, 6257-6264. 
22 J. Chen, S. Wang, J. Huang, L. Chen, L. Ma and X. Huang, ChemSusChem, 2013, 6, 1545-1555.

23 G. Akiyama, R. Matsuda, H. Sato, M. Takata and S. Kitagawa, Adv. Mater., 2011, 23, 3294-3297.

24 G. Akiyama, R. Matsuda, H. Sato and S. Kitagawa, Chem. Asian J., 2014, 9, 2772-2777.

25 J. Chen, K. Li, L. Chen, R. Liu, X. Huang and D. Ye, Green Chem., 2014, 16, 2490-2499.

26 R. DiCosimo, J. McAuliffe, A. J. Poulose and G. Bohlmann, Chem. Soc. Rev., 2013, 42, 6437-6474.

27 A. Herbst, A. Khutia and C. Janiak, Inorg. Chem., 2014, 53, 7319-7333.

28 (a) T. D. Swift, H. Nguyen, Z. Erdman, J. S. Kruger, V. Nikolakis and D. G. Vlachos, J. Catal., 2016, 333, 149-161; (b) I. Jiménez-Morales, A. Teckchandani-Ortiz, J. Santamaría-González, P. Maireles-Torres and A. JiménezLópez, Appl. Catal., B, 2014, 144, 22-28; (c) J. Wang, J. Ren, X. Liu, J. Xi, Q. Xia, Y. Zu, G. Lu and Y. Wang, Green Chem., 2012, 14, 2506-2512; (d) H. Yan, Y. Yang, D. Tong, X. Xiang and C. Hu, Catal. Commun., 2009, 10, 1558-1563.

29 (a) A. Khutia, H. Urs Rammelberg, T. Schmidt, S. Henninger and C. Janiak, Chem. Mater., 2013, 25, 790-798; (b) J. Ehrenmann, S. K. Henninger and C. Janiak, Eur. J. Inorg. Chem., 2011, 471-474.

30 G. Akiyama, R. Matsuda, H. Sato, A. Hori, M. Takata and S. Kitagawa, Microporous Mesoporous Mater., 2012, 157, 89-93.

31 M. Trivedi, Bhaskaran, A. Kumar, G. Singh, A. Kumar and N. P. Rath, New J. Chem., 2016, 40, 3109-3118; N. Cao, T. Liu, J. Su, X. Wu, W. Luo and G. Cheng, New J. Chem., 2014, 38, 4032-4035.

32 M. Saikia, D. Bhuyan and L. Saikia, New J. Chem., 2015, 39, 64-67.

33 STOE WinXPOW Version 1.10, STOE and Cie GmbH, Darmstadt, Germany, 2002.

34 Mercury - Program for Crystal Structure Visualisation, Exploration and Analysis, The Cambridge Crystallographic Data Centre (CCDC), Version 3.3.1, copyright CCDC 20012016.

35 Y. Lee, Y. Chung and W. Ahn, RSC Adv., 2014, 4, 23064-23067.

36 G. Férey, C. Mellot-Draznieks, C. Serre, F. Millange, J. Dutour, S. Surble and I. Margiolaki, Science, 2005, 309, 2040-2042.

37 T. Zhao, F. Jeremias, I. Boldog, B. Nguyen, S. K. Henninger and C. Janiak, Dalton Trans., 2015, 44, 16791-16801.

38 Y. K. Hwang, D.-Y. Hong, J.-S. Chang, S. H. Jhung, Y.-K. Seo, J. Kim, A. Vimont, M. Daturi, C. Serre and G. Férey, Angew. Chem., Int. Ed., 2008, 47, 4144-4148.

39 D.-Y. Hong, Y. K. Hwang, C. Serre, G. Férey and J.-S. Chang, Adv. Funct. Mater., 2009, 19, 1537-1552.

40 K. Brandenburg, Diamond (Version 3.2), crystal and molecular structure visualization, Crystal Impact, K. Brandenburg \& H. Putz Gbr, Bonn, Germany, 2007-2012.
41 M. Lammert, S. Bernt, F. Vermoortele, D. E. De Vos and N. Stock, Inorg. Chem., 2013, 52, 8521-8528.

42 (a) M. Thommes, K. Kaneko, A. V. Neimark, J. P. Olivier, F. Rodriguez-Reinoso, J. Rouquerol and K. S. W. Sing, Pure Appl. Chem., 2015, 87, 1051-1069; (b) K. S. W. Sing, D. H. Everett, R. A. W. Haul, L. Moscou, R. A. Pierotti, J. Rouquerol and T. Siemieniewska, Pure Appl. Chem., 1985, 57, 603-619.

43 A. Dhakshinamoorthy, M. Opanasenko, J. Cejka and H. Garcia, Catal. Sci. Technol., 2013, 3, 2509-2540.

44 (a) J. Chen, K. Li, R. Liu, X. Huang and D. Ye, Green Chem., 2014, 16, 2490-2499; (b) S. Chen, T. Yokoi, C. Tang, L. Jang, T. Tatsumi, J. C. C. Chan and S. Cheng, Green Chem., 2011, 13, 2920-2930; (c) Y. Zang, J. Shi, F. Zhang, Y. Zhong and W. Zhu, Catal. Sci. Technol., 2013, 3, 2044-2049; (d) Z. Hasan, J. W. Jun and S. H. Jhung, Chem. Eng. J., 2015, 278, 265-271.

45 R. C. Klet, Y. Liu, T. C. Wang, J. T. Hupp and O. K. Farha, J. Mater. Chem. A, 2016, 4, 1479-1485.

46 K. M. Gupta, K. Zhang and J. Jiang, Sci. Rep., 2015, 5, 12821-12830.

47 P. Bai and J. I. Siepmann, AIChE J., 2013, 59, 3523-3529.

48 Y. Yang, C. Hu and M. M. Abu-Omar, Green Chem., 2012, 14, 509-513.

49 I. Sádaba, M. López Granados, A. Riisager and E. Taarning, Green Chem., 2015, 17, 4133-4145.

50 J. Lange, Angew. Chem., 2015, 127, 13382-13394.

51 G. Tsilomelekis, M. J. Orella, Z. Lin, Z. Cheng, W. Zheng, V. Nikolakis and D. G. Vlachos, Green Chem., 2016, 18, 1983-1993.

52 Y. J. Pagan-Torres, T. Wang, J. M. R. Gallo, B. H. Shanks and J. A. Dumesic, ACS Catal., 2012, 2, 930-934.

53 Z. Fang, B. Liu, J. Luo, Y. Ren and Z. Zhang, Biomass Bioenergy, 2014, 60, 171-177.

54 R. Otomo, T. Yokoi, J. N. Kondo and T. Tatsumi, Appl. Catal., A, 2014, 470, 318-326.

55 R. van Putten, J. N. M. Soetedjo, E. A. Pidko, J. C. van der Waal, E. J. M. Hensen, E. de Jong and H. J. Heeres, ChemSusChem, 2013, 6, 1681-1687.

56 P. Wrigstedt, J. Keskiväli, M. Leskelä and T. Repo, ChemCatChem, 2015, 7, 501-507.

57 M. A. Mellmer, J. M. R. Gallo, D. M. Alonso and J. A. Dumesic, ACS Catal., 2015, 5, 3354-3359.

58 Y. Su, G. Chang, Z. Zhang, H. Xing, B. Su, Q. Yang, Q. Ren, Y. Yang and Z. Bao, AIChE J., 2016, DOI: 10.1002/aic.15356.

59 A. Dhakshinamoorthy and H. Garcia, ChemSusChem, 2014, 7, 2392-2410.

60 (a) C. Yu and J. He, Chem. Commun., 2012, 48, 4933-4940; (b) R. De Clercq, M. Dusselier, C. Christiaens, J. Dijkmans, R. I. Iacobescu, Y. Pontikes and B. F. Sels, ACS Catal., 2015, 5, 5803-5811; (c) S. H. A. M. Leenders, R. l. Gramage-Doria, B. de Bruin and J. N. H. Reek, Chem. Soc. Rev., 2015, 44, 433-448. 